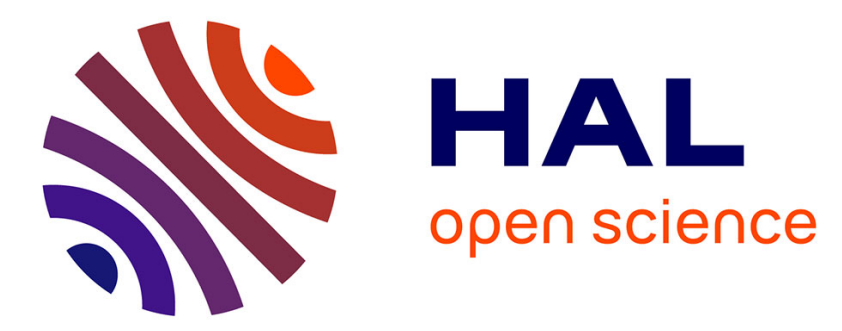

\title{
Binary Superlattices from Mo132 Polyoxometalates and Maghemite Nanocrystals: Long-Range Ordering and Fine-Tuning of Dipole Interactions
}

Romain Breitwieser, Thomas Auvray, Florence Volatron, Caroline Salzemann, Anh-Tu Ngo, Pierre-Antoine Albouy, Anna Proust, Christophe Petit

\section{To cite this version:}

Romain Breitwieser, Thomas Auvray, Florence Volatron, Caroline Salzemann, Anh-Tu Ngo, et al.. Binary Superlattices from Mo132 Polyoxometalates and Maghemite Nanocrystals: Long-Range Ordering and Fine-Tuning of Dipole Interactions. Small, 2016, 12 (2), pp.220-228. 10.1002/smll.201502127 . hal-01480743

\section{HAL Id: hal-01480743 \\ https://hal.science/hal-01480743}

Submitted on 27 Mar 2017

HAL is a multi-disciplinary open access archive for the deposit and dissemination of scientific research documents, whether they are published or not. The documents may come from teaching and research institutions in France or abroad, or from public or private research centers.
L'archive ouverte pluridisciplinaire HAL, est destinée au dépôt et à la diffusion de documents scientifiques de niveau recherche, publiés ou non, émanant des établissements d'enseignement et de recherche français ou étrangers, des laboratoires publics ou privés. 


\section{Long-range Ordering and Fine-tuning of Dipole Interactions}

3

Romain Breitwieser, Thomas Auvray, Florence Volatron, Caroline Salzemann, Anh.-Tu Ngo, Pierre-Antoine Albouy, Anna Proust*, and Christophe Petit*

Dr. R Breitwieser, T. Auvray, Dr. F. Volatron, Prof. A. Proust

9 Sorbonne Universités, UPMC Univ Paris 06, CNRS UMR, 8232,

10 Institut Parisien de Chimie Moléculaire, Université Pierre et Marie Curie, 4 place Jussieu,

11 case courrier 42, F-75005 Paris Cedex 05, France.

12 Anna.proust@upmc.fr

Dr. R Breitwieser, T. Auvray, Dr. C. Salzemann, Dr. A.-T. Ngo, Prof. C. Petit

Sorbonne Universités, UPMC Univ Paris 06, CNRS, UMR 8233, MONARIS, Case courrier

52, Université Pierre et Marie Curie, 4 place Jussieu, F-75005, Paris, France

Christophe.petit@,upmc.fr

Dr. P.-A. Albouy

Laboratoire de Physique des solides, UMR CNRS 8502

Université Paris Sud, Bât. 510, 91405 Orsay Cedex, France

24 Kewords: Maghemites, polyoxometalates, binary superlattices, $\left\{\mathrm{Mo}_{132}\right\}$, magnetic dipolar 25 interactions 


\section{Abstract}

2 In the present article, the successful coassembly of spherical $6.2 \mathrm{~nm}$-maghemite $\left(\gamma-\mathrm{Fe}_{2} \mathrm{O}_{3}\right)$

3 nanocrystals and giant polyoxometalates (POMs) such as $2.9 \mathrm{~nm}-\left\{\mathrm{Mo}_{132}\right\}$ is demonstrated. To

4 do so, colloidal solutions of oleic acid-capped $\gamma-\mathrm{Fe}_{2} \mathrm{O}_{3}$ and long chain alkylammonium-

5 encapsulated $\left\{\mathrm{Mo}_{132}\right\}$ dispersed in chloroform are mixed together and supported self-

6 organized binary superlattices are obtained upon the solvent evaporation on immersed

7 substrates. Both electronic microscopy and small angles X-ray scattering data reveal an AB-

8 type structure and an enhanced structuration of the magnetic nanocrystals (MNCs) assembly

9 with POMs in octahedral interstices. Therefore, $\left\{\mathrm{Mo}_{132}\right\}$ acts as an efficient binder constituent

10 for improving the nanocrystals ordering in three-dimensional films. Interestingly, in the case

11 of didodecyldimethylammonium $\left(\mathrm{C}_{12}\right)$ encapsulated POMs, the long-range ordered binary

12 assemblies are obtained while preserving the nanocrystals magnetic properties due to weak

13 POMs-MNCs interactions. On the other hand, POMs of larger effective diameter can be

14 employed as spacer blocks for MNCs as shown by using $\left\{\mathrm{Mo}_{132}\right\}$ capped with

15 dioctadecyldimethylammonium $\left(\mathrm{C}_{18}\right)$ displaying longer chains. In that case, we show that

16 POMs can also be used for fine-tuning the dipolar interactions in $\gamma-\mathrm{Fe}_{2} \mathrm{O}_{3}$ nanocrystal

17 assemblies. 


\section{Introduction}

2

3 Functional materials displaying long-range ordered nanostructures are the focus of intensive

4 research. For example, binary nanocrystal superlattices (BNSLs) can be described as

5 materials made of the periodical arrangement of nanocrystals of different nature and/or size. ${ }^{[1]}$

6 The self-assembly of nano-objects with various physical properties is an elegant and cheap

7 bottom-up approach allowing to design multifunctional materials at the nanometric scale.

8 Moreover, the highly ordered structure and well-defined stoichiometry of the BNSLs permits

9 a precise control of the multifunctional properties. Over the last decade, numerous BNSLs

10 from metallic, metal-chalcogenide and metal-halogenide nanocrystals have been elaborated ${ }^{[2]}$

11 and a large number of binary materials with emergent properties in electronics, ${ }^{[3]}$ magnetics, ${ }^{[4]}$

12 optics $^{[5]}$ and catalysis ${ }^{[6]}$ have been reported.

13 In the present paper, BNSLs made of the self-assembly of magnetic nanocrystals (MNCs) and

14 polyoxometalates (POMs) are studied. POMs are anionic molecular oxides of nanometric size

15 formed by the early transition metals $(\mathrm{W}, \mathrm{Mo}, \mathrm{V} \ldots)$ in their highest oxidation state. ${ }^{[7]}$ From a

16 structural point of view, POMs display a wide diversity of structures, sizes and shapes and

17 their counter-cations can be easily replaced by long-chain alkylammonium cations conferring

18 to them inorganic core/organic shell structure and solubility properties similar to those of

19 nanocrystals. ${ }^{[8]}$ The formation of BNSLs can thus be expected with POMs, while freeing itself

20 from the problematic of polydispersity, non-existent in these atomically defined clusters.

21 Moreover, POMs present proper physical properties, particularly electro- or photo-reduction,

22 and magnetism. ${ }^{[9]}$ These species are thus very promising for the elaboration of new binary

23 materials with emergent properties.

24 Although the association of POMs with nanocrystals is a well-illustrated subject, it has mainly

25 been driven by applications in the fields of catalysis, drug delivery and biosensors. ${ }^{[10]}$ In most 
cases the POMs are in direct weak contact with the nanoparticles as they play the role of the

2 protecting shell (the NCs core/POMs shell nanostructures are obtained by reduction of the

3 metal salts in the presence of the POMs, or by ligand-exchange reactions). The POMs can

4 also be anchored onto the NCs by electrostatic interaction between a cationic protecting

5 organic shell and the polyanions. ${ }^{[11]}$ But as far as we know, a single publication has reported

6 BNSLs incorporating POMs, and, in that case, semi-conductor nanocrystals. ${ }^{[12]}$ In the present

7 paper, the self-assembly of POMs and magnetic nanocrystals to form POMs/MNCs BNSLs is

8 described and the effect of the presence of the POMs on the MNCs film structuration as well

9 as on the magnetic properties is investigated.

\section{Results and discussion}

In the present binary system, we used spherical elements that are the Keplerate type $\left\{\mathrm{Mo}_{132}\right\}$

POMs in combination with maghemite MNCs $\left(\gamma-\mathrm{Fe}_{2} \mathrm{O}_{3}\right)$. Nanocrystals of $6.25 \pm 0.50 \mathrm{~nm}$ in

diameter were synthesized by thermal decomposition of iron chloride at high temperature by following a method ${ }^{[13]}$ similar to that reported by Park et al. ${ }^{[14]}$ (see Experimental section). In this way, the MNCs are characterized by a low dispersion in size of $\sim 7.5 \%$ favoring their selfassembly (Figure S1 in supporting information). On the other hand, we used the $2.9 \mathrm{~nm}$ $\left[\mathrm{Mo}_{132} \mathrm{O}_{372}\left(\mathrm{CH}_{3} \mathrm{COO}\right)_{30}\left(\mathrm{H}_{2} \mathrm{O}\right)_{72}\right]^{42-}\left\{\mathrm{Mo}_{132}\right\}$ POM as a smaller component of the superlattices. $\left\{\mathrm{Mo}_{132}\right\}$ is a $\mathrm{C}_{60}$-like hollow spherical POM with icosahedral symmetry. ${ }^{[15]}$ As illustrated in

21 Figure 1a, its structure consists of 12 fivefold symmetrical units Mo-Mos linked by $30 \mathrm{Mo}_{2}$ groups which are in turn stabilized by acetate ligands. Though it does not show proper physical properties, $\left\{\mathrm{Mo}_{132}\right\}$ has been used as a case study of POMs/MNCs binary assemblies

24 due to its large size and suitable shape. Indeed, this choice of binary elements therefore compromises (i) The necessity to use monodisperse MNCs large enough to favor their self- 
1 organization $^{[16]}$ and (ii) The need for large POMs to get a reasonable size ratio between

2 smaller and larger binary constituents that is a key parameter to form binary 3 superlattices. ${ }^{[17],[18]}$

5 The use of hydrophobic and long alkyl chains sorbed on the POMs and MNCs surfaces

6 confers solubility properties, avoids the formation of aggregates through short-range steric

7 repulsion and therefore favors a sphere-like crystallization of the building blocks. Such organic surfactants also prevent phase separation through the minimization of POMs-POMs, MNCs-MNCs and POMs-MNCs interactions as electrostatic repulsion or van der Waals attractions. In this study, we partially exchanged the $\mathrm{NH}_{4}{ }^{+}$counter-ions of $\left\{\mathrm{Mo}_{132}\right\}$ with

11 hydrophobic didodecyldimethylammonium cations (DDA ${ }^{+}$) with two $\mathrm{C}_{12}$ chains leading to the $(\mathrm{DDA})_{27}\left(\mathrm{NH}_{4}\right)_{15}\left[\mathrm{Mo}_{132} \mathrm{O}_{372}\left(\mathrm{CH}_{3} \mathrm{COO}\right)_{30}\left(\mathrm{H}_{2} \mathrm{O}\right)_{72}\right]$ species highly soluble in chloroform. Besides, oleic acid-capped $\gamma-\mathrm{Fe}_{2} \mathrm{O}_{3}$ were synthesized and dispersed in the same solvent. It was thus possible to mix colloidal solutions of POMs and $\gamma-\mathrm{Fe}_{2} \mathrm{O}_{3}$ dispersed in a common solvent with particles in weak interactions.

In entropy-driven crystallization and hard-sphere approximation, it is possible to predict the binary structures that are thermodynamically stable. The packing symmetry mainly depends on the effective size ratio between smaller and larger spheres. ${ }^{[1 \mathrm{~d}, 12,17 \mathrm{a}, 18]}$ In the present study, the effective size ratio is given by $\gamma=d_{\text {DDA-POM }} / d_{\mathrm{OA}-\mathrm{Fe} 2 \mathrm{O} 3}=(2.90+2 \times 1.2) /(6.25+2 \times 1.1)=0.63$

21 where $1.2 \mathrm{~nm}$ is the length of DDAs and $1.1 \mathrm{~nm}$ the effective length of OA chains. Here the 22 length of OA molecules has been estimated by TEM from half of the interparticle distance in 23 a maghemite close-packed assembly (Figure S1). This reduced effective length -in 24 comparison with the $\sim 1.8 \mathrm{~nm}$ nominal length- is ascribed to interdigitation of the alkyl chains. 25 In this case, $\mathrm{AlB}_{2}$-type and $\mathrm{NaZn}_{13}$-type close-packed structures are expected. ${ }^{[18,}$ 19] 
1 Accordingly, we mixed colloidal solutions of DDA- $\left\{\mathrm{Mo}_{132}\right\}$ and $\mathrm{OA}-\gamma-\mathrm{Fe}_{2} \mathrm{O}_{3}$ with a 2:1 ratio

2 to get $\mathrm{AlB}_{2}$-type structures. The POMs and MNCs were dispersed in chloroform with molar

3 concentrations of particles $\sim 10 \mu \mathrm{M}$ and $5 \mu \mathrm{M}$ respectively and mixed in equal volumetric

4 proportion. Supported binary assemblies were then obtained upon the solvent evaporation on immersed highly ordered pyrolytic graphite (HOPG) or amorphous carbon coated TEM grid substrates (Figure $1 \mathrm{~b}$ and $\mathrm{c}$ ). Here the crucial parameters are mainly the control of the temperature and atmosphere. Optimal conditions were found with the substrate kept at $20^{\circ} \mathrm{C}$ together with a $\mathrm{CHCl}_{3}$-saturated atmosphere in order to slow down the solvent evaporation rate (see Experimental section). In this way, we demonstrate the successful coassembly of DDA- $\left\{\mathrm{Mo}_{132}\right\}$ and $\mathrm{OA}-\gamma-\mathrm{Fe}_{2} \mathrm{O}_{3} \mathrm{MNCs}$ as shown hereafter.

The field emission gun-scanning electron microscopy (FEG-SEM) image of Figure 2a reveals a close-packed assembly of the nanocrystals on HOPG. The miscibility of POMs and MNCs is shown by energy dispersive X-rays spectroscopy (EDS) through the Mo $\mathrm{L}_{\alpha}$ and Fe $\mathrm{K}_{\alpha}$ signals (2.293 kV and $6.398 \mathrm{kV}$ resp.) detected from the same sample area (Figure $\mathbf{2 b}$ ). The quantitative analysis shows relative atomic $\mathrm{Mo} / \mathrm{Fe}$ composition $\sim 0.049$ which is in good agreement with the expected atomic ratio $\sim 0.056$ from a $2: 1 \mathrm{POM} / \mathrm{NC}$ ratio. The latter has been estimated by considering $132 \mathrm{Mo}$ atoms per POM and a $6.2 \mathrm{~nm}$ maghemite NC of 221 cubic unit cells with the composition $\left(\mathrm{Fe}^{3+}\right)_{8}\left(\mathrm{Fe}^{3+}{ }_{5 / 6} \cdot \square_{1 / 6}\right)_{16} \mathrm{O}_{32}$ where the brackets identify tetrahedral and octahedral sites of ferric ions and the square symbol refers to the iron 21 vacancies. FEG-SEM images typically show long-range ordered domains of DDA$22\left\{\mathrm{Mo}_{132}\right\} / \mathrm{OA}-\gamma-\mathrm{Fe}_{2} \mathrm{O}_{3} \mathrm{MNCs}$ on $\mathrm{HOPG}$ expanding over $\sim 1 \mu \mathrm{m}^{2}$. From closer view by TEM, 23 we observed typical [111]-projected hexagonal lattices of close-packed nanocrystal bilayers 24 showing relatively large domains $\left(>500 \mathrm{~nm}^{2}\right)$ on amorphous carbon-coated grids (Figure 2c). 25 The higher magnification TEM image in Figure 2d reveals more clearly the presence of 
1 DDA- $\left\{\mathrm{Mo}_{132}\right\}$ at the center of the hexagonal MNCs lattice indicating the presence of POMs

2 in octahedral interstices. This thermodynamically unexpected AB-type structure is illustrated

3 in inset and discussed later in this article. The weak electronic contrast of the molecular

4 clusters is pointed out and attributed to the low Mo density compared to Fe in maghemites. ${ }^{[12]}$

5 In addition to this 1:1 binary structure, we also observed small surrounding patches of POMs

6 by TEM $\left(<50 \mathrm{~nm}^{2}\right.$, see Figure S2) explaining the larger 2:1 $\left\{\mathrm{Mo}_{132}\right\} / \gamma-\mathrm{Fe}_{2} \mathrm{O}_{3}$ atomic ratio

7 probed by SEM-EDS from a volume of primary excitation $\sim \mu \mathrm{m}^{3}$. Nevertheless, we

8 demonstrate for the first time the capability to design POMs/MNCs binary superlattices.

9

Interestingly, we observed POMs-induced effects on the structure of a few layers-thick films.

11 Indeed, as reported in literature, ${ }^{[13]}$ pure $\gamma-\mathrm{Fe}_{2} \mathrm{O}_{3}$ films show cracks that originate from

12 accumulated stress $v s$ thickness (Figure 3a). In binary thin films prepared in the same

13 conditions, we observed that the density of such cracks drastically decreases with cracks-free

14 areas extending over $\sim 1 \mu \mathrm{m}^{2}$. The DDA- $\left\{\mathrm{Mo}_{132}\right\}$ inserted in the MNCs octahedral interstices

15 therefore reduces stress and strengthen the film cohesion. Furthermore, an enhanced $\gamma-\mathrm{Fe}_{2} \mathrm{O}_{3}$

16 ordering in the binary superlattices is revealed by fast Fourier transform analysis that

17 indicates single domain orientations (hexagonal pattern) within $\sim 1 \mu \mathrm{m}^{2}$ areas while pure

18 maghemites are characterized by multiple domain orientations (multiple spots) at this scale

19 (inset of Figure 3b and 3a resp.). Thus, both of these in-plane structuring effects lead to

20 long-range defects-free and ordered MNCs making this binary system industrially relevant.

22 The maghemites structure in the binary superlattices was further investigated by grazing 23 incidence small angle X-ray scattering (GISAXS), in particular to distinguish whether the 24 close-packed MNCs lattice is cubic (fcc) or hexagonal (hcp). The GISAXS measurements were performed using a homemade system with a copper anode (details in Experimental 
1 section). ${ }^{[20]}$ For this study, we prepared thick binary assemblies on HOPG ( hundred layers of

2 binary $\mathrm{MNCs} / \mathrm{POMs}$ ) together with reference samples made of MNCs only obtained in the

3 same deposition conditions. From the sample-detector distance and the spot coordinates, we

4 determined the Bragg angle $2 \theta_{B}$ and therefore the modulus of the diffracted vector $\boldsymbol{q}$ from the

5 Bragg relation. We also estimated the core-to-core interparticle distance $D_{c-c}$ from the position

6 of Bragg reflections i.e. from the interplanar stacking periodicities $d$ along the normal to the

7 surface $\boldsymbol{q}_{z}\left(D_{c-c}=d \times \sqrt{ }(3 / 2)\right) .{ }^{[21]}$ Our results show that binary and reference samples give similar

8 GISAXS patterns as shown in Figure 4a and b. Both patterns show strong first-order Bragg

9 reflections and the second-order is also detected. The thin films therefore have (111) plans

10 preferentially oriented parallel to the surface. We also point out the presence of elongated

11 spots that is due to the presence of stacking faults. ${ }^{[21]}$ Thus, it is difficult to distinguish an hep

12 from an fcc structure in these statistical crystals. Nevertheless, a long-range ordering in the

13 binary thin film is deduced from plots of normalized intensities $v s 2 \theta$ along $\boldsymbol{q}_{z}$ (Figure $4 \mathbf{c}$ ).

14 Indeed, the half-width $\delta q_{1 / 2}$ of the first-order reflection peak - related to the correlation length

$15-$ is $\sim 0.04 \mathrm{~nm}^{-1}$ (empty squares) that is close to the experimental resolution $\left(\sim 0.03 \mathrm{~nm}^{-1}\right)$. We

16 also notice that $\delta q_{1 / 2}$ measured for the reference sample significantly increases $\left(\sim 0.07 \mathrm{~nm}^{-1}\right)$

17 indicating a lower ordering along $\boldsymbol{q}_{z}$ in pure maghemite films (filled circles). Here the POMs-

18 induced better structuring corroborates the enhanced in-plan ordering observed by TEM

19 (Figure 3b). Furthermore, the line profiles along $\boldsymbol{q}_{z}$ show similar stacking periodicities $\sim 7.00$

$20 \pm 0.05 \mathrm{~nm}\left(D_{c-c} \sim 8.60 \pm 0.05 \mathrm{~nm}\right)$ and $\sim 7.10 \pm 0.05 \mathrm{~nm}\left(D_{c-c} \sim 8.70 \pm 0.05 \mathrm{~nm}\right)$ for binary and

21 pure $\mathrm{OA}-\gamma-\mathrm{Fe}_{2} \mathrm{O}_{3}$ assemblies respectively. Thus the MNCs structure is not distorted by the

22 presence of POMs. This is understood by simple geometrical considerations since $2.9 \mathrm{~nm}$ -

$23\left\{\mathrm{Mo}_{132}\right\}$ can be easily inserted into the $\mathrm{OA}-\gamma-\mathrm{Fe}_{2} \mathrm{O}_{3}$ octahedral interstice of $3.6 \mathrm{~nm}$ (estimated

24 from experimental $D_{c-c}$ ) by considering partial DDA-OA interdigitation (see illustration in 
1 Figure 4d). Here we anticipate that magnetic dipole-dipole interactions between MNCs

2 should not be modified in the binary superlattices.

4 The magnetic properties of dozen layers-thick DDA- $\left\{\mathrm{Mo}_{132}\right\} / \mathrm{OA}-\gamma-\mathrm{Fe}_{2} \mathrm{O}_{3}$ binary

5 assemblies/HOPG have been characterized using a superconducting quantum interference

6 device (SQUID) magnetometer. The superparamagnetic behavior of the nanocrystals was

7 probed by performing field-cooling/zero-field cooling (FC/ZFC) measurements of

8 magnetization $v s$ temperature $(3-300 \mathrm{~K})$ in an in-plane field of 100 Oe. As expected for 6.2

9 nm-maghemite MNCs, the temperature dependence of the magnetization shows a maximum

10 in ZFC curves corresponding to the ferromagnetic-superparamagnetic (i.e. blocked-

11 unblocked) transition (Figure 5a). Moreover, the nanocrystals feel weak dipole-dipole

12 interactions at very low temperature as indicated by the change of slope in FC curves. Thus,

13 the temperature at the ZFC maximum -related to the magnetic anisotropy energy- depends on

14 the dipolar interactions in addition to the MNCs volume. Hereafter the term $T_{B}$ refers to this

15 specific temperature. Our results show that both $\gamma-\mathrm{Fe}_{2} \mathrm{O}_{3}$ (line) and binary (open symbols)

16 superlattices exhibit strictly the same temperature dependence with $T_{B} \sim 22.2 \mathrm{~K}$. Moreover, the

17 hysteresis loops show the same ferromagnetic behavior at $3 \mathrm{~K}$ with a coercitivity $H_{c} \sim 163$ Oe,

18 a saturation field $H_{s a t} \sim 3.25 \mathrm{kOe}$ and a remanence $M_{r} / M_{s} \sim 0.3$ (Figure 5b). It is worth noting

19 that structural and magnetic characterizations are consistent. We therefore show that we are

20 able to grow binary POMs/MNCs superlattices leading to an enhanced ordering of the

21 nanocrystals while preserving their magnetic properties.

23 The size effect of POMs on the binary assembly properties was investigated by using $\left\{\mathrm{Mo}_{132}\right\}$

24 capped with dioctadecyl-dimethylammonium (DODA) $\left(\mathrm{C}_{18}\right.$ chains of $\sim 1.8 \mathrm{~nm}$ in length). The 25 depositions were realized after keeping the mixture at ambient conditions for at least four 
1 days to get long-range ordered binary domains. Despite the change of the constituents size

2 ratio $(\gamma=0.77)$, the self-organization leads to the same AB-type structure. It is shown in the

3 TEM images of Figure 6 where POMs are inserted in the octahedral interstices of close-

4 packed maghemite bi-layers. Here the interparticle distance $\sim 9.6 \mathrm{~nm}$ (Figure 6) which is

5 larger than the distance measured in pure $\mathrm{OA}-\gamma-\mathrm{Fe}_{2} \mathrm{O}_{3}$ assemblies $\left(D_{c-c} \sim 8.4 \mathrm{~nm}\right.$, Figure S1).

7 GISAXS experiments were realized for thin three-dimensional ( $\sim$ dozen layers) binary 8 assemblies on $\mathrm{HOPG}$ and for the corresponding pure $\mathrm{OA}-\gamma-\mathrm{Fe}_{2} \mathrm{O}_{3}$ reference samples. From 9 the plots of normalized intensity $v_{s} 2 \theta$ along $\boldsymbol{q}_{z}$ (Figure 7c), we show that using DODA$10\left\{\mathrm{Mo}_{132}\right\}$ in the binary assembly increases the interparticle distance from $8.20 \pm 0.05 \mathrm{~nm}$ 11 (reference) to $9.10 \pm 0.05 \mathrm{~nm}$. Such a tendency to increase $D_{c-c}$ is consistent with the TEM images reported above and was observed by FEG-SEM too, the latter showing $D_{c-c} \sim 9.5 \mathrm{~nm}$ and $\sim 8.2 \mathrm{~nm}$ for the binary and reference samples respectively (line profiles from Figure 7d and 7e). Compared to the value of $8.70 \mathrm{~nm}$ given above for pure maghemite films ( $\sim$ hundred layers), we also note that $D_{c-c}$ increases with the thickness that is probably due to the stressrelaxation and the numerous stacking faults in thicker assemblies. It is worth mentioning that such a thickness dependence of the interparticle distance has not been observed in the binary films most likely due to the POMs-induced structuring effect (Figure S3). The long-range order of the MNCs combined with DODA- $\left\{\mathrm{Mo}_{132}\right\}$ is revealed by the reduced and nearly resolution-limited $\delta q_{1 / 2} \sim 0.03 \mathrm{~nm}^{-1}\left(\delta q_{1 / 2} \sim 0.05 \mathrm{~nm}^{-1}\right.$ for the reference). Furthermore, in contrast with the diffraction pattern of maghemite films, the binary film is characterized by multiple (111) diffraction spots with many different orientations. Here the presence of randomlyoriented crystals is clearly involved suggesting that homogeneous nucleation occurs in 24 addition to the layer-by-layer growth observed by TEM and FEG-SEM. The long maturing time of the mixture might be involved. However, the growth mechanisms and also the driving 
1 force leading to the unexpected AB-type binary superlattices remain open questions.

2 Preliminary observations suggest that entropy is not the main contribution to the binary self-

3 assembly since (i) No binary assemblies were observed by performing depositions at

4 temperatures exceeding $25^{\circ} \mathrm{C}$ and (ii) Only AB-type structures were obtained either by

5 mixing POMs and MNCs with various ratio (4:1, 10:1, 15:1 and 20:1) or by changing the

6 constituents size ratio as shown with DDA- and DODA- $\left\{\mathrm{Mo}_{132}\right\}$. Additional interactions, like

7 electrostatic ${ }^{[22]}$ or van der Waals forces, ${ }^{[16]}$ predominant at the nanometric scale, might

8 contribute to the formation of the POMs/MNCs BNSL. This point is still under study.

9

FC/ZFC SQUID measurements of magnetization $v s$ temperature were performed for dozen

11 layers-thick DODA- $\left\{\mathrm{Mo}_{132}\right\} / \gamma-\mathrm{Fe}_{2} \mathrm{O}_{3}$ assemblies. In comparison with the magnetic response

of $\mathrm{OA}-\gamma-\mathrm{Fe}_{2} \mathrm{O}_{3}$ assemblies prepared in the same conditions (Figure 8, solid line), we show

that $\mathrm{T}_{\mathrm{B}}$ of the binary thin film shifts toward lower temperature from $22.8 \mathrm{~K}$ to $20.8 \mathrm{~K}$ that is

$14 \sim 10 \%$ of $\mathrm{T}_{\mathrm{B}}$ (open circles). In regards to the increase of the interparticle distance by $\sim 1 \mathrm{~nm}$ reported above with DODA- $\left\{\mathrm{Mo}_{132}\right\}$, we attribute the decreasing of $\mathrm{T}_{\mathrm{B}}$ to reduced dipolar interactions. In order to avoid any misinterpretation of this small shift and to distinguish

17 physical effects from artefacts, the experiments were reproduced several times and performed 18 by using different magnetometers (SQUID and Vibrating Sample Magnetometer). Moreover, similar effects were observed for binary assemblies prepared from colloids dispersed in toluene (Figure S4). We also point out that according to the variation of $\mathrm{T}_{\mathrm{B}}$ vs $D_{c-c}$ reported in

21 the literature for interacting iron oxide nanoparticles, ${ }^{[23]}$ a $\Delta \mathrm{T}_{\mathrm{B}} \sim 2 \mathrm{~K}$ should correspond to

$22 \Delta D_{c-c} \sim 1 \mathrm{~nm}$, which is in good agreement with our results. As a reference, we join the FC/ZFC 23 measurements obtained for non-interacting $\gamma-\mathrm{Fe}_{2} \mathrm{O}_{3}$ nanocrystals diluted in chloroform 24 (Figure S5, $\mathrm{T}_{\mathrm{B}} \sim 13.7 \mathrm{~K}$ ). Those results therefore show that encapsulated $\left\{\mathrm{Mo}_{132}\right\}$ can be used 
as spacer building blocks in binary assemblies for the fine-tuning of dipole interactions

2 between $\gamma-\mathrm{Fe}_{2} \mathrm{O}_{3} \mathrm{MNCs}$.

\section{Conclusion}

6 In conclusion, we have shown that designing polyoxometalates (POMs)/magnetic 7 nanocrystals (MNCs) binary superlattices is possible. In particular, we demonstrate the 8 successful coassembly of $\left\{\mathrm{Mo}_{132}\right\}$ POMs and $\gamma-\mathrm{Fe}_{2} \mathrm{O}_{3}$ MNCs. The binary material was

9 realized by mixing colloidal solutions of alkylammonium-encapsulated $\left\{\mathrm{Mo}_{132}\right\}$ and oleic acid-capped $\gamma-\mathrm{Fe}_{2} \mathrm{O}_{3}$ dispersed in chloroform. Upon solvent evaporation in specific

11 conditions, supported binary superlattices displaying an AB-type structure have been obtained 12 on HOPG substrates. Interestingly, the POMs inserted in octahedral MNCs interstices act as 13 binder constituents increasing the film cohesion and leading to an enhanced ordering of the nanocrystals. In the case of DDA $\left(\mathrm{C}_{12}\right)$ encapsulated POMs, we observed that such a structuring effect can be obtained while preserving the magnetic properties of $\gamma-\mathrm{Fe}_{2} \mathrm{O}_{3}$ thanks to surfactant-induced weak interactions. We have also reported that using $\left\{\mathrm{Mo}_{132}\right\}$ capped with longer chains (DODA i.e. $\mathrm{C}_{18}$ ) increases the interparticle distance and consequently decreases dipole-dipole magnetic interactions. Thus, POMs of suitable size can also be used as spacer building blocks to modulate the magnetic properties in MNCs assemblies. Both structuring and magnetic effects in these binary assemblies have strong implications for making defect-free magnetic nanocrystal arrays with long-range ordering and controlled

22 collective dipolar interactions. It might be particularly interesting for high-density data storage applications to combine POMs with other MNCs of enhanced magnetic anisotropy

24 such as $\mathrm{FePt},{ }^{[24]} \mathrm{CoPt},{ }^{[25]} \mathrm{Co},{ }^{[26]}$ etc. In addition to a variety of nanocrystals and nanoalloys, 25 the large diversity of POMs showing proper properties (redox, magnetic, catalytic etc.) brings 
new opportunities to get synergetic effects between the binary constituents for magnetic, electronic, spintronic, catalytic and other applications. To do so, further investigation on the nucleation/growth and self-organization mechanisms -under study- is needed, especially in order to control the structures and properties of such superlattices.

\section{Experimental Section}

Chemicals. For the synthesis of oleic acid-capped $\gamma-\mathrm{Fe}_{2} \mathrm{O}_{3}$, iron chloride $\left(\mathrm{FeCl}_{3} .6 \mathrm{H}_{2} \mathrm{O}, 99 \%\right)$ was purchased from Prolabo, sodium oleate $\left(\mathrm{C}_{18} \mathrm{H}_{33} \mathrm{NaO}_{2}, 97 \%\right)$ from TCI, oleic acid $(90 \%)$ and 1-octadecene (90\%) from Sigma-Aldrich.

Synthesis of $\gamma-\mathrm{Fe}_{2} \mathrm{O}_{3}$ nanocrystals. The maghemite nanocrystals were prepared by modifying the synthesis reported by Park et al. ${ }^{[14]}$ In particular, we used 1-octadecene as solvent instead of 1-hexadecene in order to obtain $\sim 6.2 \mathrm{~nm}$ iron oxide nanocrystals. ${ }^{[13]}$ Firstly, we synthesized the iron-oleate complex by mixing iron chloride, $\left(\mathrm{FeCl}_{3} \cdot 6 \mathrm{H}_{2} \mathrm{O}\right)$ and sodium oleate in a solvent mixture of hexane, ethanol and distilled water. The mixture was refluxed at $66^{\circ} \mathrm{C}$ for $4 \mathrm{~h}$ and the organic phase was washed three times with ultrapure water $(30 \mathrm{ml})$ in a separatory funnel. The residual hexane present in the organic phase was evaporated under vacuum in a rotavapor at $32^{\circ} \mathrm{C}$. The paste of iron-oleate complex was then dissolved in $150 \mathrm{ml}$ of hexane and again evaporated at $32^{\circ} \mathrm{C}$. Secondly, we synthesized maghemite nanocrystals from $1.42 \mathrm{~g}$ of ironoleate complex dissolved in a mixture of $10 \mathrm{ml}$ of 1 -octadecene and $0.9 \mathrm{~g}$ of oleic acid at room temperature. This mixture was heated up to $317^{\circ} \mathrm{C}$ (i.e. the boiling point of 1octadecene) under vigorous stirring and was refluxed for 30 min then cooled down to room 
1 temperature. In this way, we obtained a black gel containing the maghemite nanocrystals. The

2 nanocrystals were finally separated and washed with a large excess of ethanol and acetone

3 mixture. The binary samples were then prepared from colloidal solutions of maghemites

4 dispersed in chloroform.

6 Synthesis of $\left\{M_{132}\right\}$ Polyoxometalates and counter-cations exchange. The $7 \quad\left(\mathrm{NH}_{4}\right)_{42}\left[\mathrm{Mo}_{132} \mathrm{O}_{372}\left(\mathrm{CH}_{3} \mathrm{COO}\right)_{30}\left(\mathrm{H}_{2} \mathrm{O}\right)_{72}\right] \cdot 300 \mathrm{H}_{2} \mathrm{O} \cdot 10 \mathrm{CH}_{3} \mathrm{COONH}_{4}$ was synthesized as 8 described in the literature. ${ }^{[27]}$ The $\mathrm{NH}_{4}{ }^{+}$counter-cations were then exchanged by adapting 9 well-known procedures ${ }^{[8,12,28]}$ : the $\left\{\mathrm{Mo}_{132}\right\}$ species were transferred in an organic phase by 10 adding $n$ equivalent of DDA or DODA solubilized in chloroform $(n=60$ for DDA, $n=42$ for 11 DODA) to a $5.10^{-4} \mathrm{M}$ solution of $\left(\mathrm{NH}_{4}\right)_{42}\left[\mathrm{Mo}_{132} \mathrm{O}_{372}\left(\mathrm{CH}_{3} \mathrm{COO}\right)_{30}\left(\mathrm{H}_{2} \mathrm{O}\right)_{72}\right]$ in water under vigorous stirring. The dark brown chloroform phase was separated, washed twice with water and the product was then precipitated with three volumes of methanol and dried under 14 vacuum. The dark brown precipitate was obtained with a 70-80 \% yield. $(\text { DDA })_{27}\left(\mathrm{NH}_{4}\right)_{15}\left[\mathrm{Mo}_{132} \mathrm{O}_{372}\left(\mathrm{CH}_{3} \mathrm{COO}\right)_{30}\left(\mathrm{H}_{2} \mathrm{O}\right)_{72}\right] \cdot 10 \mathrm{H}_{2} \mathrm{O}: \mathrm{FT}-\mathrm{IR} / \mathrm{cm}^{-1}$ (KBr pellet) 2923 (s), $2852(\mathrm{~s}), 1627(\mathrm{~m}), 1549(\mathrm{~m}), 1465(\mathrm{~m}), 983(\mathrm{~s}), 952(\mathrm{~m}), 857$ (s), $805(\mathrm{~s}), 733(\mathrm{~s}), 632(\mathrm{mw})$, 574 (s) ; Elemental analysis (\%) calcd: C 28.19, H 5.63, N 1.81, Mo 39.01; found: C 28.72, H 5.62, N 1.14, Mo 39.7, $\mathrm{Br}<200 \mathrm{ppm}$; TGA under $\mathrm{N}_{2}: 4.1 \%$ of weight loss between $20^{\circ} \mathrm{C}$ and $220^{\circ} \mathrm{C}$ corresponding to the $\mathrm{H}_{2} \mathrm{O}$ molecules (theoretical weight loss $4.5 \%$ ) $(\text { DODA })_{32}\left(\mathrm{NH}_{4}\right)_{10}\left[\mathrm{Mo}_{132} \mathrm{O}_{372}\left(\mathrm{CH}_{3} \mathrm{COO}\right)_{30}\left(\mathrm{H}_{2} \mathrm{O}\right)_{72}\right] \cdot 70 \mathrm{H}_{2} \mathrm{O}: \mathrm{FT}-\mathrm{IR} / \mathrm{cm}^{-1} \quad(\mathrm{KBr}$ pellet $) 2919$ (s), 2850 (s), 1626 (m), 1557 (m), 1467 (m), $984(\mathrm{~s}), 952$ (m), 860 (s), 808 (s), 735 (s), 636 (mw), 575 (s) ; Elemental analysis (\%) calcd: C 37.61, H 7.30, N 1.44; found: C 37.79, H

$237.31, \mathrm{~N} 1.16$; TGA under $\mathrm{N}_{2}: 6.8 \%$ of weight loss between $20^{\circ} \mathrm{C}$ and $220^{\circ} \mathrm{C}$ corresponding 24 to the $\mathrm{H}_{2} \mathrm{O}$ molecules (theoretical weight loss $6.3 \%$ ). 
1 Samples preparation. Colloidal binary solutions were prepared from equal volumetric

2 mixtures of alkylammonium- $\left\{\mathrm{Mo}_{132}\right\}$ dispersed in $\mathrm{CHCl}_{3}(10 \mu \mathrm{M})$ and oleic acid-capped

3 maghemite $\mathrm{MNCs}$ dispersed in the same solvent $(5 \mu \mathrm{M})$. Supported coassemblies were then

4 obtained using a dip method by drying the mixture directly on horizontally immersed HOPG

5 or amorphous carbon TEM grids. We were able to grow binary superlattices by controlling

6 the substrate temperature. To do so, we used a thermo-regulated copper block to keep the

7 substrate at $20^{\circ} \mathrm{C}$. In addition, the vial was placed in a hermetically covered cell and the

8 depositions were realized in $\mathrm{CHCl}_{3}$-saturated atmosphere in order to slow down the

9 evaporation rate $(\sim 12$ hours for $200 \mu \mathrm{L})$. The volume of binary solution was deposited

10 according to the substrates size. The TEM grids were immersed in 20 to $30 \mu \mathrm{L}$ giving $\sim 1-10$

11 MNCs layers. HOPG substrates of $10 \times 5 \mathrm{~mm}^{2}$ were immersed in 200 to $800 \mu \mathrm{L}$ giving

12 thickness from dozen to hundred MNCs layers. It is worth mentioning that samples made

13 from the binary mixture were accompanied with reference samples of pure maghemite

14 nanocrystals grown in identical conditions for better comparison.

Samples characterization. A 100 kV transmission electron microscope (TEM, JEOL JEM-

1011) was used to characterize both maghemite and binary assemblies. Imaging and energy dispersive X-rays spectroscopy (EDS) microanalysis were performed with a SU-70 Hitachi FEG-SEM and an X-Max $50 \mathrm{~mm}^{2}$ Oxford EDX detector. Hysteresis loops at $3 \mathrm{~K}$ and thermal dependence of the $\gamma-\mathrm{Fe}_{2} \mathrm{O}_{3}$ magnetization $(3-300 \mathrm{~K}$ ) were measured with a commercial SQUID magnetometer (Cryogenic S600) with applied fields up to $4 \mathrm{~T}$. Grazing incidence small-angle $\mathrm{X}$-ray scattering measurements were performed using a homemade system $^{38}$. The $\mathrm{K}_{\alpha}$

23 radiation $\left(\lambda=0.1542 \mathrm{~nm}\right.$ ) from a rotating copper anode generator (small focus $0.1 \times 0.1 \mathrm{~mm}^{2}$, $2440 \mathrm{kV}, 20 \mathrm{~mA}$ ) is selected with a parallel beam multilayer optics. Incidence angle on the 
1 substrate surface is varied between zero and a few degrees using a rotation stage. Diffraction

2 patterns are recorded on photostimulable imaging plates.

3

4 Supporting Information

5 Supporting Information is available from the Wiley Online Library or from the author.

6

\section{$7 \quad$ Acknowledgements}

8 This work was supported by the LabEx MiChem, part of French state funds managed by the

9 ANR within the "Investissements d'Avenir" program under reference ANR-11-IDEX-0004$10 \quad 02$.

11 The authors thank D. Montero (IMPC) for FEG-SEM characterization. FEG-SEM 12 instrumentation was facilitated by the IMPC FR2482 (Institut des Matériaux de Paris Centre) 13 financially supported by the C'Nano projects of the Région Ile-de-France. Acknowledgments 14 are given to Dr. N. Goubet and Dr. J. Richardi (MONARIS Laboratory) for fruitful 15 discussions. The authors also thank Prof. P. Gouzerh for his precious advices about the POMs 16 synthesis and characterization.

[1] a) D. V. Talapin, J. S. Lee, M. V. Kovalenko, E. V. Shevchenko, Chem. Rev. 2010, 110, 389; b) D. Vanmaekelbergh, Nano Today 2011, 6, 419; c) C. J. Kiely, J. Fink, M. Brust, D. Bethell, D. J. Schiffrin, Nature 1998, 396, 444; d) F. X. Redl, K. S. Cho, C. B.

[2] a) Z. Yang, J. Wei, P. Bonville, M.-P. Pileni, J. Am. Chem. Soc. 2015, 137, 4487; b) E. 
Mat. 2015, 2846; c) H. Friedrich, C. J. Gommes, K. Overgaag, J. D. Meeldijk, W. H. Evers, B. de Nijs, M. P. Boneschanscher, P. E. de Jongh, A. J. Verkleij, K. P. de Jong, A. van Blaaderen, D. Vanmaekelbergh, Nano Lett. 2009, 9, 2719; d) T. Paik, C. B. Murray, Nano Lett. 2013, 13, 2952; e) T. Zheng, L. D. Sun, J. C. Zhou, W. Feng, C. Zhang, C. H. Yan, Chem. Commun. 2013, 49, 5799.

[3] J. J. Urban, D. V. Talapin, E. V. Shevchenko, C. R. Kagan, C. B. Murray, Nat. Mater. 2007, 6, 115.

[4] a) H. Zeng, J. Li, J. P. Liu, Z. L. Wang, S. H. Sun, Nature. 2002, 420, 395; b) J. Chen, A. G. Dong, J. Cai, X. C. Ye, Y. J. Kang, J. M. Kikkawa, C. B. Murray, Nano Lett. 2010, 10, 5103; c) A. G. Dong, J. Chen, X. C. Ye, J. M. Kikkawa, C. B. Murray, J. Am. Chem. Soc. 2011, 133, 13296; d) A. G. Dong, J. Chen, P. M. Vora, J. M. Kikkawa, C. B. Murray, Nature. 2010, 466, 474; e) J. Chen, X. C. Ye, S. J. Oh, J. M. Kikkawa, C. R. Kagan, C. B. Murray, ACS Nano. 2013, 7, 1478.

[5] X. C. Ye, J. Chen, B. T. Diroll, C. B. Murray, Nano Lett. 2013, 13, 1291.

[6] Y. J. Kang, X. C. Ye, J. Chen, Y. Cai, R. E. Diaz, R. R. Adzic, E. A. Stach, C. B. Murray, J. Am. Chem. Soc. 2013, 135, 42.

[7] M. T. Pope, Comprehensive Coordination Chemistry. Wedd, A. ed.; Mc Cleverty, J. A. Meyer, T. J. Elsevier Ltd: Oxford, 2004; Vol. 4.

[8] D. Volkmer, A. Du Chesne, D. G. Kurth, H. Schnablegger, P. Lehmann, M. J. Koop, A. Muller, J. Am. Chem. Soc. 2000, 122, 1995.

[9] a) T. Yamase, Chem. Rev. 1998, 98, 307; b) M. Sadakane, E. Steckhan, Chem. Rev. 1998, 98, 219; c) J. M. Clemente-Juan, E. Coronado, A. Gaita-Arino, Chem. Soc. Rev. 2012, 41, 7464; d) P. Kogerler, B. Tsukerblat, A. Muller, Dalton T. 2010, 39, 21.

[10] a) Y. F. Wang, I. A. Weinstock, Chem. Soc. Rev. 2012, 41, 7479; b) S. G. Mitchell, J. M. de la Fuente, J. Mater. Chem. 2012, 22, 18091; c) R. Villanneau, A. Roucoux, P. 
Beaunier, D. Brouri, A. Proust, RSC Adv. 2014, 4, 26491; d) K. M. Seemann, A. Bauer, J. Kindervater, M. Meyer, C. Besson, M. Luysberg, P. Durkin, W. PyckhoutHintzen, N. Budisa, R. Georgii, C. M. Schneider, P. Kogerler, Nanoscale. 2013, 5, 2511; e) J. Huang, W. Y. Liu, D. S. Dolzhnikov, L. Protesescu, M. V. Kovalenko, B. Koo, S. Chattopadhyay, E. V. Shenchenko, D. V. Talapin, ACS Nano. 2014, 8, 9388.

[11] a) M. Masteri-Farahani, J. Movassagh, F. Taghavi, P. Eghbali, F. Salimi, Chem. Eng. J. 2012, 184, 342; b) J. Gooch, A. A. Jalan, S. Jones, C. R. Hine, R. Alam, S. Garai, M. M. Maye, A. Muller, J. Zubieta, J. Colloid. Interf. Sci. 2014, 432, 144.

[12] M. I. Bodnarchuk, R. Erni, F. Krumeich, M. V. Kovalenko, Nano Lett. 2013, 13, 1699.

[13] A.-T. Ngo, J. Richardi, M. P. Pileni, Phys. Chem. Chem. Phys. 2013, 15, 10666.

[14] J. Park, K. An, Y. Hwang, J.-G. Park, H.-J. Noh, J.-Y. Kim, J.-H. Park, N.-M. Hwang, T. Hyeon, Nat. Mater. 2004, 3, 891.

[15] E. K. A. Muller, H. Bogge, M. Schidtmann, F. Peters, Angew. Chem. Int. Ed. 1998, 37, 3360.

[16] A. C. H. Brune, C. Petit and V. Repain, Self-assembly of nano-alloys in Nanoalloys: From Fundamentals to Emergent Applications. Elsevier: 2013.

[17] a) M. D. Eldridge, P. A. Madden, D. Frenkel, Nature 1993, 365, 35; b) N. Hunt, R. Jardine, P. Bartlett, Phys. Rev. E. 2000, 62, 900.

[18] J. V. Sanders, M. J. Murray, Close-packed structures of spheres of two different sizes II. The packing densities of likely arrangements. Philos. Mag. 1980, p 721.

[19] P. Bartlett, R. H. Ottewill, P. N. Pusey, J. Chem. Phys. 1990, 93, 1299.

[20] A. Courty, A. Mermet, P. A. Albouy, E. Duval, M. P. Pileni, Nat. Mater. 2005, 4, 395.

[21] A. I. Henry, A. Courty, M. P. Pileni, P. A. Albouy, J. Israelachvili, J. Am. Chem. Soc. 2008, 8, 2000. 
1 [22] M. I. Bodnarchuk, M. V. Kovalenko, W. Heiss, D. V. Talapin, J. Am. Chem. Soc. 2010, 132, 11967.

[23] C. J. Bae, S. Angappane, J.-G. Park, Y. Lee, J. Lee, K. An, T. Hyeon, Appl. Phys. Lett. 2007, 91, 102502.

[24] S. Sun, C. B. Murray, D. Weller, L. Folks, A. Moser, Science 2000, 287, 1989.

[25] F. Kameche, A.-T. Ngo, C. Salzemann, M. Cordeiro, E. Sutter, C. Petit, Phys. Chem. Chem. Phys. 2015.

[26] a) C. Petit, Z. L. Wang, M. P. Pileni, J. Phys. Chem. B. 2005, 109, 15309; b) D. Parker, I. Lisiecki, C. Salzemann, M.-P. Pileni, J. Phys. Chem. C. 2007, 111, 12632.

[27] A. Muller, E. Krickemeyer, H. Bogge, M. Schmidtmann, F. Peters, Angew. Chem. Int. Edit. 1998, 37, 3360.

[28] S. Floquet, E. Terazzi, A. Hijazi, L. Guenee, C. Piguet, E. Cadot, New J. Chem. 2012, $36,865$.

Figure 1. (a) Schematics of (left) DDA- $\left\{\mathrm{Mo}_{132}\right\}$ composed of 12 pentagonal Mo-Mos units and $30 \mathrm{Mo}_{2}$ linkers and (right) Oleic acid-capped maghemite nanocrystal. (b) Illustration of the temperature- and atmosphere-controlled dip method used to get binary superlattices on HOPG as illustrated in (c).

Figure 2. (a) FEG-SEM image of a DDA- $\left\{\mathrm{Mo}_{132}\right\} / \mathrm{OA}-\gamma-\mathrm{Fe}_{2} \mathrm{O}_{3}$ coassembly on HOPG (scale bar: $100 \mathrm{~nm}$ ). (b) Energy dispersive X-ray spectroscopy from (a). (c) Typical TEM image of [111]-projected AB-type binary superlattice from a close-packed bi-layer of MNCs (scale bar: $50 \mathrm{~nm}$ ). (d) Higher magnification TEM image of the AB-type binary superlattice (scale bar: $10 \mathrm{~nm}$ ) together with the corresponding crystallographic models. 
2 Figure 3. (a, b) TEM images of a few layers-thin film of single $\mathrm{OA}-\gamma-\mathrm{Fe}_{2} \mathrm{O}_{3}$ and DDA$3\left\{\mathrm{Mo}_{132}\right\} / \mathrm{OA}-\gamma-\mathrm{Fe}_{2} \mathrm{O}_{3}$ binary assembly respectively (scale bar: 100 nm). Insets indicate 4 selected-area FFT analysis.

6 Figure 4. $(\mathrm{a}, \mathrm{b}) \mathrm{GISAXS}$ patterns from $\sim$ hundred layers-thick films of DDA- $\left\{\mathrm{Mo}_{132}\right\} / \mathrm{OA}-\gamma-$ $7 \quad \mathrm{Fe}_{2} \mathrm{O}_{3}$ and single $\mathrm{OA}-\gamma-\mathrm{Fe}_{2} \mathrm{O}_{3}$ respectively. (c) Normalized intensity $v s .2 \theta$ along $\boldsymbol{q}_{z}$ from (a,b) 8 giving the core-to-core interparticle distance and therefore the octahedral interstice size of the 9 close-packed $\mathrm{OA}-\gamma-\mathrm{Fe}_{2} \mathrm{O}_{3}$ structure. (d) Illustration of the NCs unit cell and the POM 10 insertion in the octahedral interstice.

Figure 5. SQUID measurements of $\mathrm{OA}-\gamma-\mathrm{Fe}_{2} \mathrm{O}_{3}$ magnetization for a DDA- $\left\{\mathrm{Mo}_{132}\right\} / \mathrm{OA}-\gamma-$ $\mathrm{Fe}_{2} \mathrm{O}_{3}$ binary thin film (open circles) and for a pure MNCs thin film (solid line). The temperature-dependence (FC and ZFC measured with in-plan field of $100 \mathrm{Oe}$ ) and the in-plan field-dependence (measured at $3 \mathrm{~K}$ ) are shown in (a) and (b) respectively.

Figure 6. TEM images of a DODA- $\left\{\mathrm{Mo}_{132}\right\} / \mathrm{OA}-\gamma-\mathrm{Fe}_{2} \mathrm{O}_{3}$ binary superlattice together with a line profile showing an interparticle distance $\sim 9.6 \mathrm{~nm}$ (scale bars: $50 \mathrm{~nm}$ and $20 \mathrm{~nm}$ ).

Figure 7. (a, b) GISAXS patterns from dozen layers-thick films of DODA- $\left\{\mathrm{Mo}_{132}\right\} / \mathrm{OA}-\gamma-$

$21 \mathrm{Fe}_{2} \mathrm{O}_{3}$ and single $\mathrm{OA}-\gamma-\mathrm{Fe}_{2} \mathrm{O}_{3}$ respectively. (c) Normalized intensity $v s .2 \theta$ along $\boldsymbol{q} z$ from (a, b). (d, e) FEG-SEM images of DODA- $\left\{\mathrm{Mo}_{132}\right\} / \mathrm{OA}-\gamma-\mathrm{Fe}_{2} \mathrm{O}_{3}$ and single $\mathrm{OA}-\gamma-\mathrm{Fe}_{2} \mathrm{O}_{3}$ assemblies respectively (scale bar: $50 \mathrm{~nm}$ ). The line profiles from (d) and (e) indicate

24 interparticle distances $\sim 9.5 \mathrm{~nm}$ and $8.2 \mathrm{~nm}$ resp. 
1 Figure 8. SQUID measurements of $\mathrm{OA}-\gamma-\mathrm{Fe}_{2} \mathrm{O}_{3}$ magnetization for a DODA- $\left\{\mathrm{Mo}_{132}\right\} / \mathrm{OA}-\gamma-$ $2 \mathrm{Fe}_{2} \mathrm{O}_{3}$ binary thin film (open circles) and for a pure MNCs thin film (solid line). The FC/ZFC 3 temperature-dependence (with in-plan field of $100 \mathrm{Oe}$ ) is shown and presented at different 4 scales.

5

6 
$\left\{\mathrm{Mo}_{132}\right\} @ D D A$

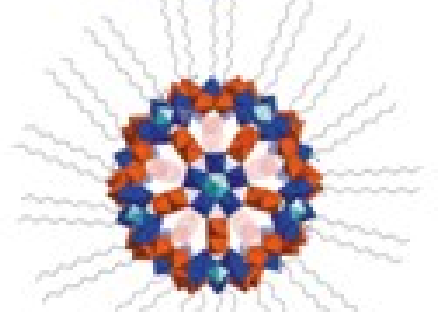

$\gamma-\mathrm{Fe}_{2} \mathrm{O}_{3} @ \mathrm{OA}$

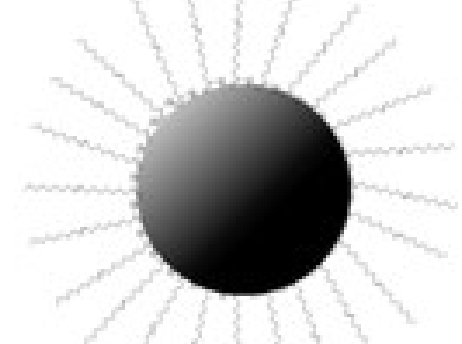

\section{HOPG}

\section{$6 \mathrm{~nm}$}

3 The successful coassembly of $\left\{\mathrm{Mo1}_{132}\right\}$ polyoxometalates (POMs) and $\gamma$-Fe $\mathrm{Fe}_{2} \mathrm{O}_{3}$ magnetic

Title: Binary superlattice from $\{$ Mo132\} polyoxometalates and maghemite nanocrystals 


\section{a. $\left\{\mathrm{Mo}_{132}\right\} \quad \gamma-\mathrm{Fe}_{2} \mathrm{O}_{3}$}

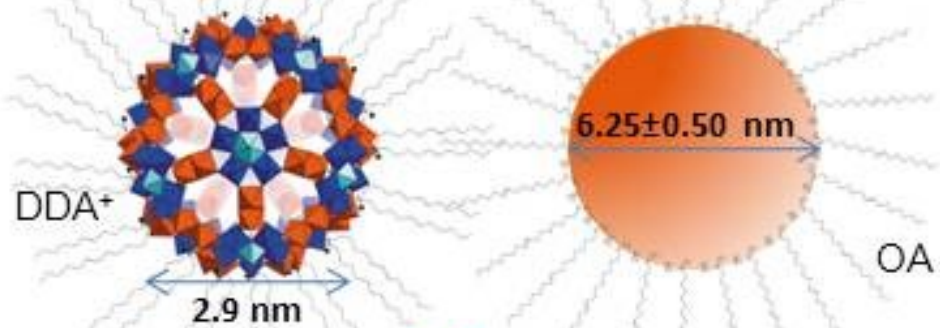

b.

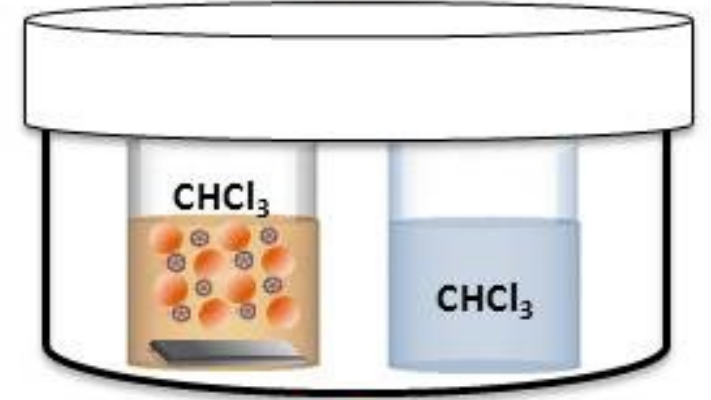

c.
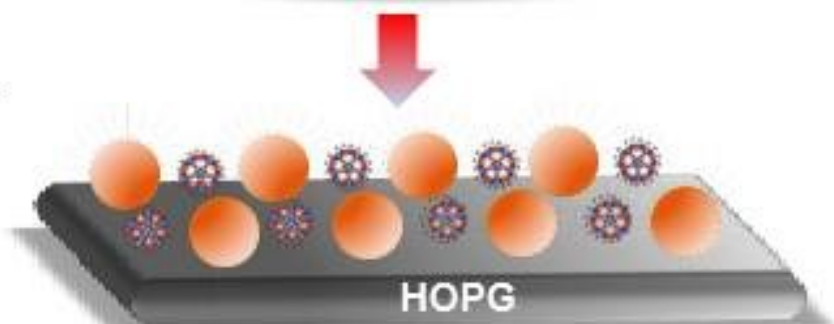

FIGURE 1.

7

8

9

10

11

12

13 

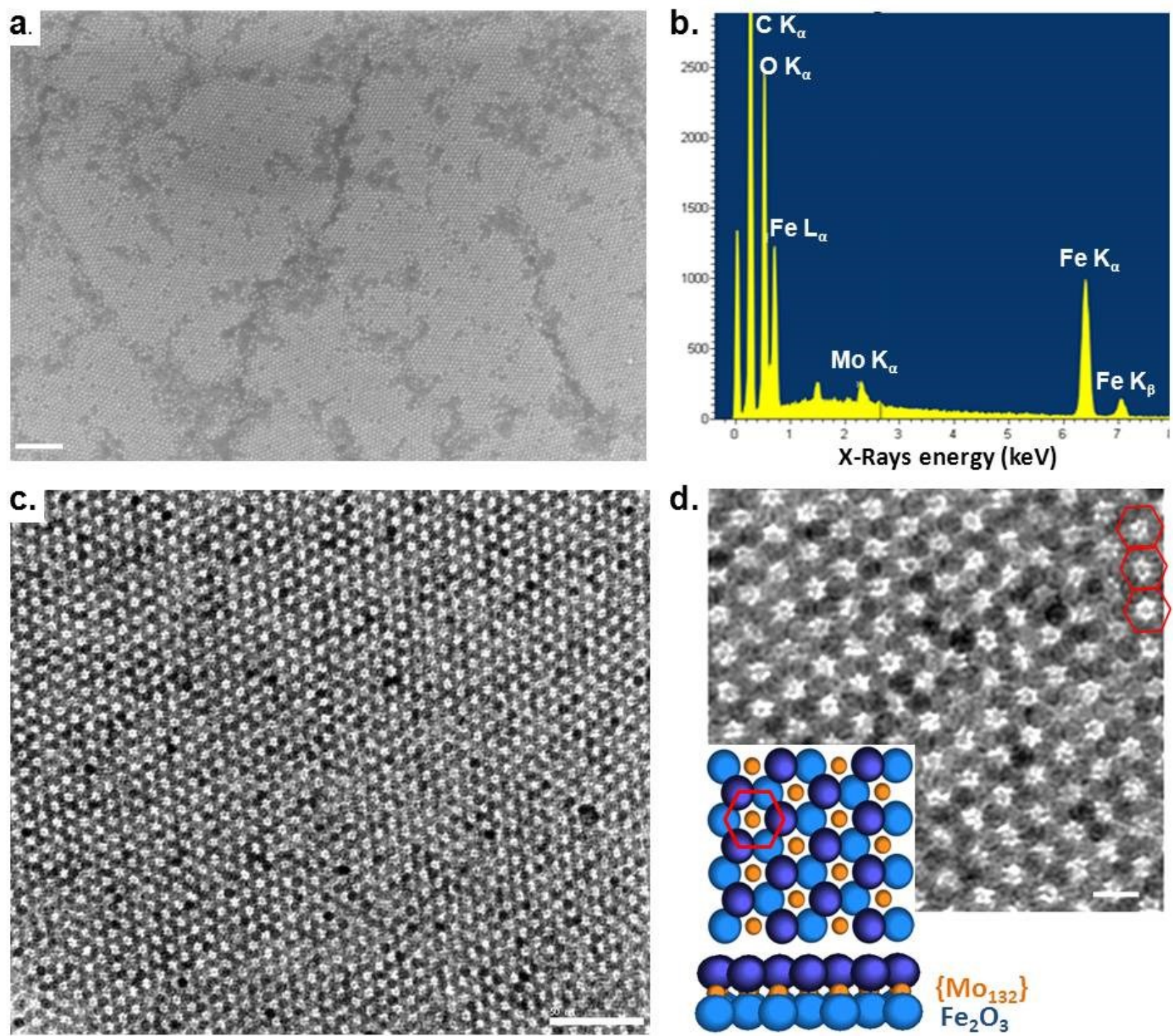

2

FIGURE 2.

4

5

6

7

8 

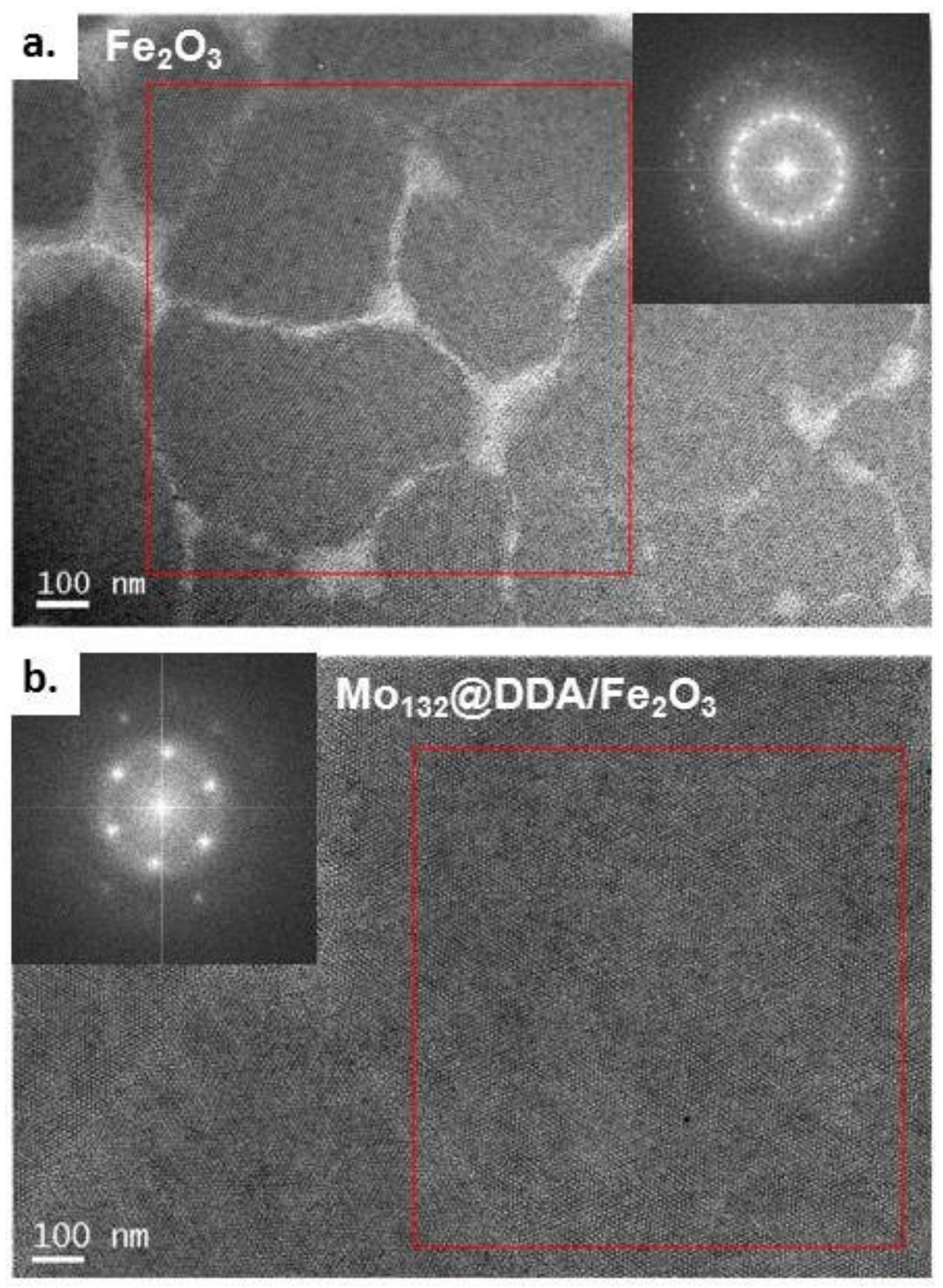

5

6 FIGURE 3.

7

8

9 
a. DDA- $\left\{\mathrm{Mo}_{132}\right\} / \gamma-\mathrm{Fe}_{2} \mathrm{O}_{3}$

b.

$\gamma-\mathrm{Fe}_{2} \mathrm{O}_{3}$

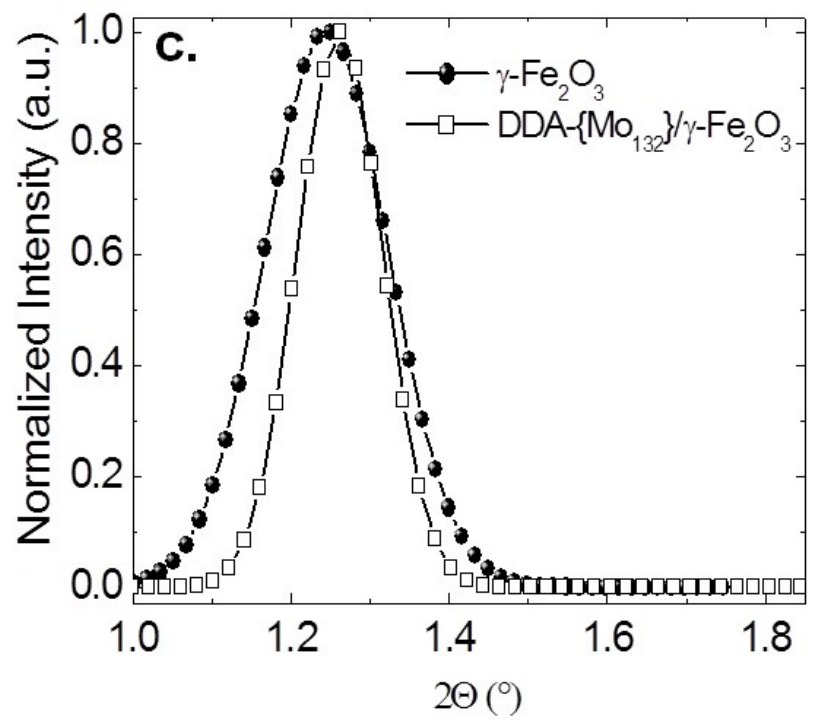

d.

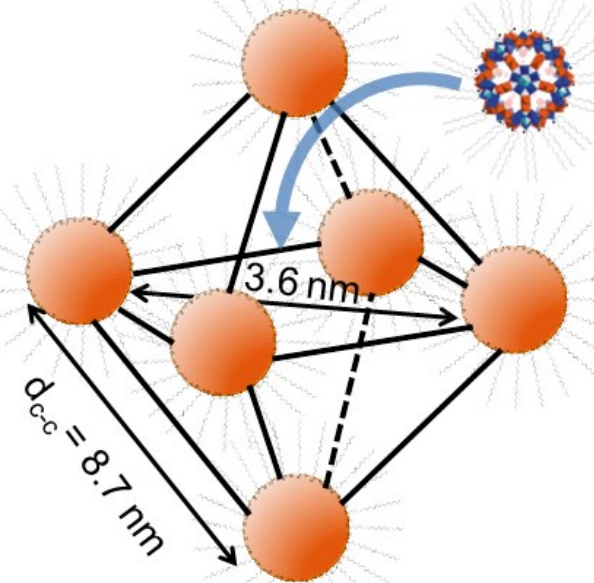

4

5 FIGURE 4.

6

7

8

9 


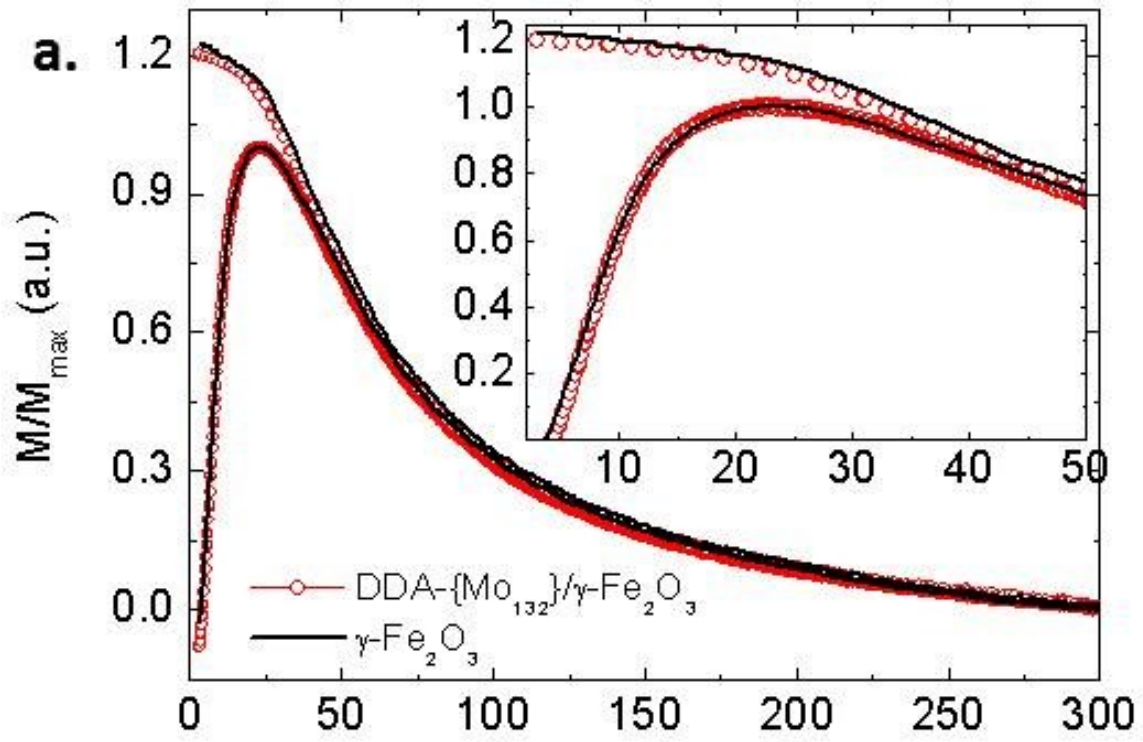

b.

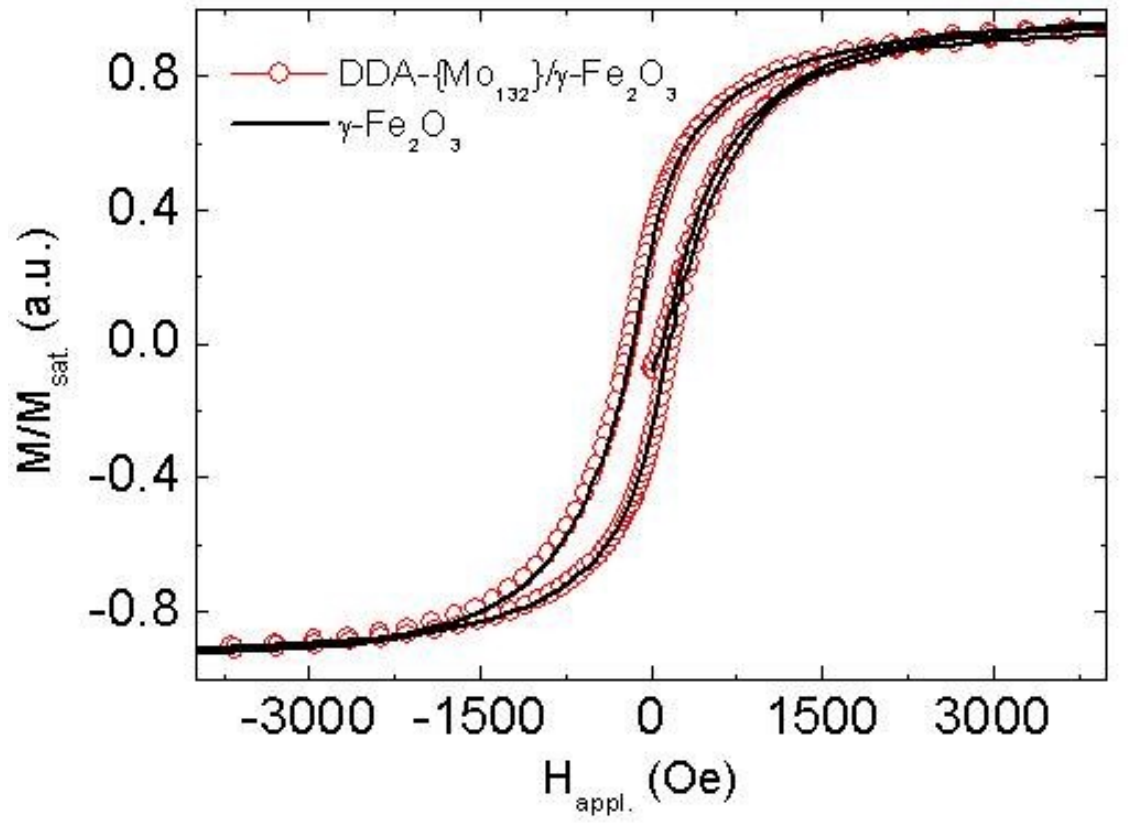

3

4

FIGURE 5. 

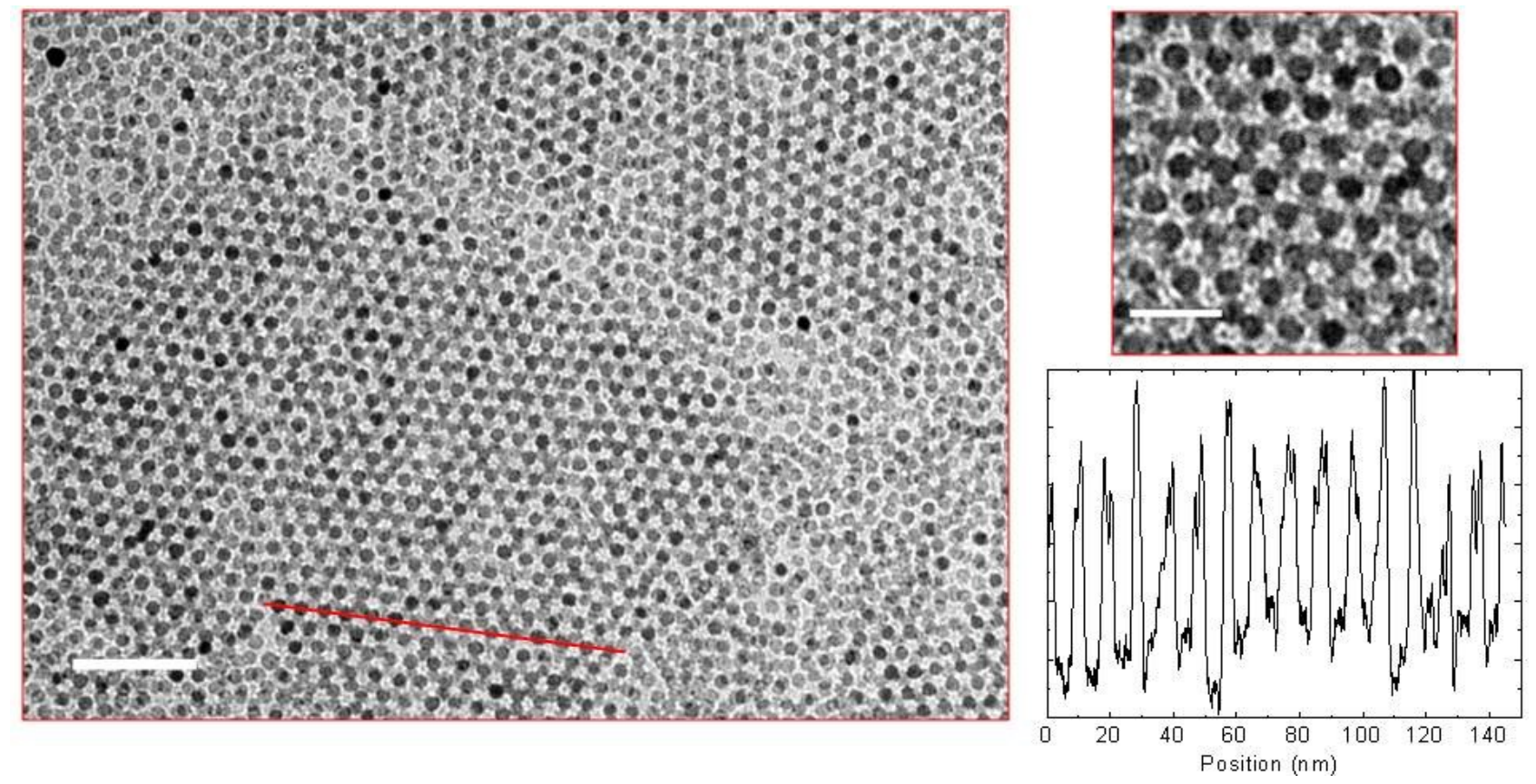

2

3

FIGURE 6.

4

5

6

7

8

9

10

11

12

13 

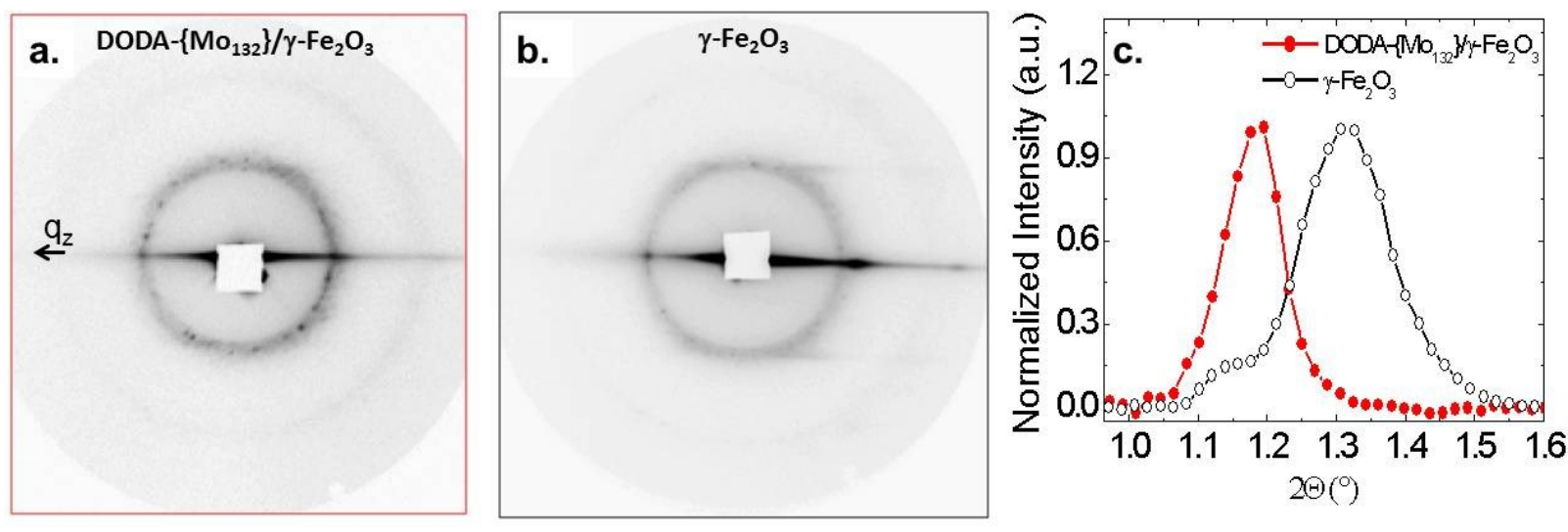

DODA- $\left\{\mathrm{Mo}_{132}\right\} / \gamma-\mathrm{Fe}_{2} \mathrm{O}_{3}$

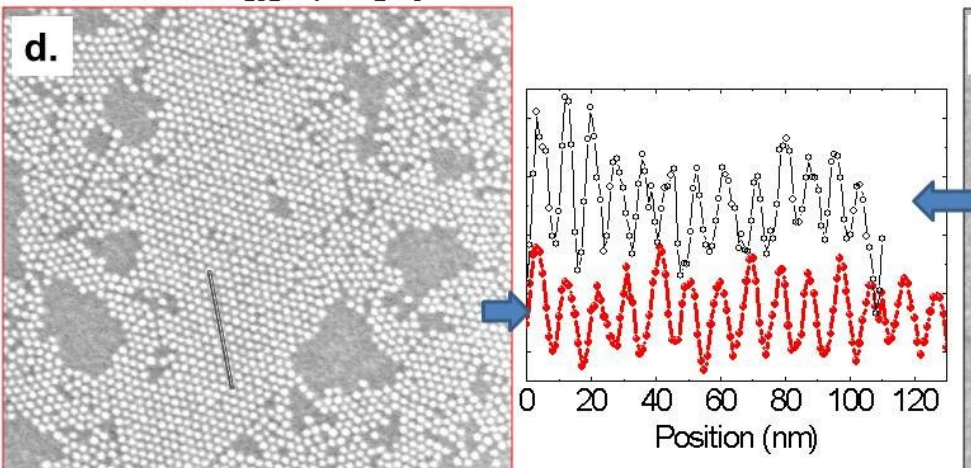

$\gamma-\mathrm{Fe}_{2} \mathrm{O}_{3}$

e. 


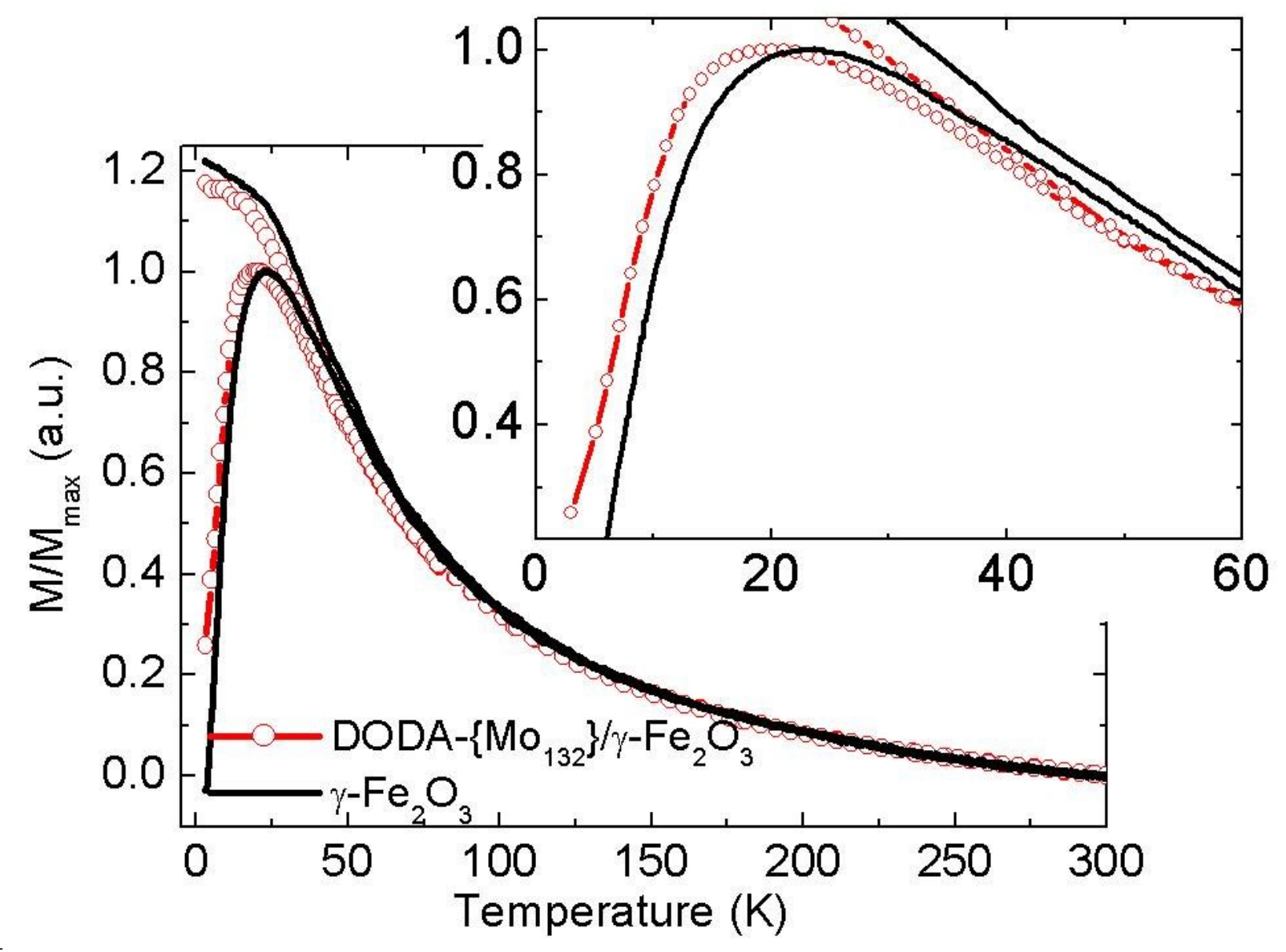

2

FIGURE 8.

3

4

5

6

7

8

9

10 